\title{
Com açúcar e sem afeto: Violência contra a mulher no contexto da Covid-19
}

\author{
With sugar and without affection: Violence against women in the context of Covid-19 \\ Con sugar y sin affection: Violencia contra la mujer en el contexto de Covid-19
}

\author{
Elaine Ferreira do Nascimento \\ ORCID: https://orcid.org/0000-0002-1632-9148 \\ Fundação Oswaldo Cruz, Brasil \\ Universidade Federal do Piauí, Brasil \\ E-mail: negraelaine@gmail.com \\ Liana Maria Ibiapina do Monte \\ ORCID: https://orcid.org/0000-0002-8339-8477 \\ Fundação Oswaldo Cruz, Brasil \\ E-mail: lianaibiapina@yahoo.com.br \\ Rodrigo Aragão da Silva \\ ORCID: https://orcid.org/0000-0002-1123-7762 \\ Universidade Federal do Piaú, Brasil \\ E-mail: aragao-rodrigo@hotmail.com \\ Francisca Kananda Lustosa dos Santos \\ ORCID: https://orcid.org/0000-0002-8545-6378 \\ Universidade Federal do Piauí, Brasil \\ E-mail: knanda.13@hotmail.com \\ Brenna Galtierrez Fortes Pessoa \\ ORCID: https://orcid.org/0000-0001-6421-5754 \\ Universidade Federal do Piauí, Brasil \\ E-mail: brennagaltierrez@hotmail.com \\ Paulo de Tarso Xavier Sousa Junior \\ ORCID: https://orcid.org/0000-0002-5493-5376 \\ Universidade Federal de Santa Maria, Brasil \\ E-mail: paulo_juniorpio@hotmail.com \\ Naína Jéssica Carvalho Araújo \\ ORCID: https://orcid.org/0000-0002-5510-956X \\ Universidade Federal do Piauí, Brasil \\ E-mail: nainacarvalho29@gmail.com \\ Luara Dias Silva \\ ORCID: https://orcid.org/0000-0001-5128-6430 \\ Universidade Federal do Piauí, Brasil \\ E-mail: luaradiasas@gmail.com
}

\begin{abstract}
Resumo
O presente artigo tem como objeto o tema da violência contra a mulher no contexto da Covid-19 e buscou responder alguns questionamentos acerca das políticas públicas de proteção da mulher contra a violência, em especial, de que forma a aplicabilidade dessas políticas está sendo garantida pelas instituições em um momento de isolamento social. Diante desse questionamento, buscou-se a partir de uma pesquisa bibliográfica compreender como a rede de proteção à mulher está se reestruturando para garantir que essa mulher vítima de violência tenha seus direitos resguardados. Foi possível evidenciar um movimento por parte dos grupos de proteção, autoridades e instituições no sentido de modernizar e diversificar as formas de acesso dessa mulher aos serviços e aparatos de proteção, por meio dos meios de comunicação, abertura de novos canais de denúncia, redes sociais e mídias digitais. Dessa forma, a pandemia proporcionou uma reinvenção deste trabalho, de modo a garantir a integridade da mulher, mesmo em situações de distanciamento social. Palavras-chave: Violência contra a mulher; Políticas públicas; Covid-19; Proteção social; Isolamento social.
\end{abstract}

\begin{abstract}
This article aims at the theme of violence against women in the context of Covid-19 and sought to answer some questions about public policies to protect women against violence, especially how the applicability of these policies is being guaranteed by institutions in a moment of social isolation. In view of this questioning, we sought from a bibliographical research to understand how the network of protection of women is restructuring to ensure that this woman victim of violence has her rights protected. It was possible to highlight a movement on the part of protection groups, authorities and institutions to modernize and diversify the forms of access of this woman to services and protection devices, through the media, opening of new channels of denunciation, social networks and digital media. Thus, the pandemic provided a reinvention of this work, in order to guarantee the integrity of women, even in situations of social distance.
\end{abstract}


Keywords: Violence against Women; Public policy; Covid-19; Social protection; Social isolation.

\section{Resumen}

Este artículo tiene como objetivo el tema de la violencia contra la mujer en el contexto de Covid-19 y se trató de responder a algunas preguntas sobre las políticas públicas para proteger a las mujeres contra la violencia, especialmente cómo la aplicabilidad de estas políticas está siendo garantizada por las instituciones en un momento de aislamiento social. En vista de este cuestionamiento, buscamos una investigación bibliográfica para entender cómo la red de protección de las mujeres se reestructura para garantizar que esta mujer víctima de la violencia tenga sus derechos protegidos. Es posible destacar un movimiento por parte de grupos de protección, autoridades e instituciones para modernizar y diversificar las formas de acceso de esta mujer a los servicios y dispositivos de protección, a través de los medios de comunicación, la apertura de nuevos canales de denuncia, redes sociales y medios digitales. Así, la pandemia brindó una reinvención de este trabajo, con el fin de garantizar la integridad de las mujeres, incluso en situaciones de distanciamiento social.

Palabras clave: Violencia contra la mujer; Política pública; Covid-19; Protección social; Aislamiento social.

\section{Introdução}

A violência, apresentada por diversas formas, se caracteriza como uma problemática existente desde os primórdios da humanidade. No clássico escrito por Émile Durkheim (1978) é possível caracterizá-la como um fato social, sendo esta, uma atitude reproduzida ao longo das sociedades as quais exercem algum tipo de poder sobre os seres humanos. Pensar em violência nos remete a figura de uma ou mais ações que por meio de determinados artifícios, utilizam de algum tipo de força para algum desejo.

Nessa perspectiva é importante lembrar de um outro agente que é envolvido nesse processo: a vítima do agressor. É bem verdade que esse fenômeno é direcionado, muitas vezes, à menor parcela da população, em que a busca pela tomada das rédeas aparentam justificar a perseguição e utilização de comportamentos agressivos (Anjos, 2019). É nesse momento que surgem formas de segregação que reiteram o poder dessas violências. Desigualdades são acirradas e a dominação caracterizada figurativamente como bélica passa a estar nas mãos dos ofensores (Sawaia, 2017).

Estudos como o de Nunes \& Sales (2016) apontam para uma raiz mais profunda dessa questão. É bem verdade que vivenciar ou ter algum tipo de contato com uma situação lesiva podem auxiliar no desenvolvimento de uma personalidade agressora. Caráter esse, renovado nas ações adultas dos seres a exemplos de roubos, assassinatos, agressões, golpes patrimoniais, violências psicológicas e afins.

Um exemplo da gravidade desse episódio e bastante discutido nos tempos atuais diz respeito a violência contra a mulher, mas se engana quem acredita ser um acontecimento novo. Santos e Izumino (2005) apontam dados assustadores, mas reais. O meio social sempre foi um carimbo para justificar os maus tratos de gênero.

Entrando mais afundo no cerne desta questão é preciso analisar as condições que levam a este fato. O que dá direito a um homem agredir e até mesmo tirar a vida de uma mulher? Independentemente das relações construídas entre esses sujeitos é notório a raiz do machismo. Corroborada ao longo dos séculos, o papel da mulher nas sociedades era nulo, onde não havia vez e voz. A submissão e obediência se tornou um dos principais elementos para ser uma mulher. Deste modo, seja por meio da política ou da saúde ou quaisquer outras áreas, os homens sempre foram dotados do poder (Teles; Melo, 2017).

Portanto, o patriarcado contribuiu para o aumento das desigualdades entre homens e mulheres, bem como demais meios de exclusão e sofrimento (Hirata, 2018). Mesmo descrito anteriormente como uma discussão mais frequente ainda na atualidade as estatísticas assustam. Apenas no ano de 2019 no Brasil foram notificados aproximadamente 145 mil casos de algum tipo de violência contra a mulher (Cubas; Zaremba; Amâncio, 2019). Antes de iniciar um apaziguamento desses e de outros casos (reduzidos na internet a termos como "mimimi" ou "feministas radicais") é notório a corroboração de ideias trazidas por Butler (2003), em que a característica do ser feminino está relacionado a dominação masculina. Poder esse exercido sobre as piores formas de agressões possíveis, combatido por meio da Lei Maria da Penha ( $\mathrm{N}^{\circ} 11.340$, de 7 de Agosto de 2006) e Lei do 
Feminicídio ( $\mathrm{N}^{\mathrm{o}}$ 13.104, de 9 de Março de 2015).

Além dos pontos anteriores, atualmente essa batalha enfrenta outro desafio: uma pandemia mundial. Tomados de maneira rápida e sem muitas explicações, o mundo convive com uma das maiores tragédias anunciadas nos últimos tempos. $\mathrm{O}$ surgimento do novo coronavírus (Covid-19) fez cidades e países inteiros adotarem políticas surpreendentes para o conflito de um inimigo invisível e mortal.

A estratégia mais comum e eficaz apontada pela ciência consiste no isolamento social. Bezerra, Silva, Soares \& Silva (2020) relatam a comprovação dos sujeitos em relação a essa forma de prevenção. Entretanto a mesma vem seguida de outras questões fundamentais como o adoecimento físico e psíquico, desemprego e dificuldades salariais, afastamento e afetamento das relações humanas, dentre outros. Pensando nisso surgem mais inquietações relevantes. Com o isolamento social as pessoas tendem a permanecer em suas casas e vítimas das consequências descritas anteriormente, a mulher que sofre violência, carrega consigo um peso maior que as demais pessoas. Analisar como este fenômeno se comporta e aparenta "sobreviver" mesmo em uma pandemia mundial é o foco deste estudo.

\section{Metodologia}

O presente estudo trata-se de uma revisão bibliográfica do tipo exploratória, qualitativa e descritiva. A pesquisa qualitativa pode ser definida como um estudo não estatístico, que identifica e analisa em profundidade dados de difícil mensuração de um determinado grupo de indivíduos em relação a um problema específico. Entre eles estão sentimentos, sensações e motivações que podem explicar determinados comportamentos, apreendidos com o foco no significado que adquirem (Minayo, 2013).

A pesquisa é caracterizada como descritiva pelo fato de apresentar os dados da forma em que se encontram. Nesse tipo de pesquisa os dados são coletados sem que haja qualquer interferência do pesquisador. É do tipo exploratória uma vez que obtemos os resultados desejados a partir do contato com determinada população (Marconi e Lakatos, 2010).

A pesquisa qualitativa proporciona compreensão em profundidade do contexto do problema. É um método indutivo por excelência para entender por que o indivíduo age como age, pensa como pensa ou sente como sente, pois, respostas em profundidade são geradas apenas pela abordagem qualitativa (Minayo, 2013).

A coleta de dados deu-se a partir da base de dados Scielo, utilizando-se para isso as palavras chave "Violência Contra a Mulher"; "Políticas Públicas", "Proteção Social", "Covid-19” e "Isolamento Social”. O recorte temporal foi de 2016 a 2020. Além da base de dados foram utilizadas leis que versam acerca das políticas públicas para mulheres dentre outros normativos. Para fins de coleta de dados, foram elencados os trabalhos que se referiam a artigos de revisão, por considerar que os mesmos possuem elementos conceituais importantes para o subsídio da discussão.

As fontes foram analisadas por meio do método de Análise de Conteúdo (Bardin, 2016). Trata-se de uma metodologia de pesquisa utilizada para descrever e fazer interpretações dos conteúdos de falas, documentos, textos - é possível fazer uso de qualquer material do qual provenha comunicação, verbal ou não-verbal.

\section{Resultados e Discussão}

\subsection{Isolamento social necessário e a convivência com o agressor}

O momento atual do Brasil tem gerado muita tensão social, o que faz com que setores considerados importantes possuam agora um cenário de incertezas, a exemplo, o setor econômico. As mulheres entram nesse cenário de forma fragilizada, pois as que exercem função remunerada conciliam o trabalho doméstico com o home office. Já as que não, terão mais trabalho (ofício não remunerado) doméstico, devido aos companheiros e/os filhos estarem mais presente no lar, causando ainda mais desgaste e 
cansaço. Além de terem mais visibilidade e controle pelos seus respectivos maridos e companheiros agressores (Okabayashi et al., 2020).

Situação esta que contribui bastante, conforme o Ministério dos Direitos Humanos, para o ensejo de comportamentos considerados violentos contra as mulheres pelos seus parceiros. Segundo o que consta na Lei Maria da Penha (11.340/06), sancionada pelo ex-presidente Luís Inácio Lula da Silva em 7 de agosto de 2006, esse fenômeno pode ocorrer de forma: psicológica, física, moral, sexual e patrimonial, que ressalta como o isolamento pode trazer uma consequência bastante desfavorável no que se diz sobre o aumento dos riscos de incidências de casos desse tipo de violência (Marques et al., 2020).

Neste sentido, a "escravidão doméstica", ambientada entre casa e cozinha, algumas mesclando com o trabalho pago, está sendo o horizonte de muitas mulheres. Mas, o que as deixam realmente fragilizadas é a ruptura dos vínculos familiares, como também dos vizinhos ou outras instituições que as mesmas frequentavam, como igreja ou outros tipos de lugares comunitários (Paz; Pires; Vieira \& Witt, 2019). As redes de apoio e proteção estão tendo que se remodelarem acerca dos cuidados em relação às mulheres em situação de violência, onde encontram-se diante de um novo universo evidenciado pelo novo coronavírus e o método de enfrentamento através do isolamento social. Diante desse novo contexto se faz necessário a modificação do fazer profissional e das políticas públicas de combate à violência contra a mulher (Melo et al., 2020).

Nesta perspectiva, enquanto para muitos o ambiente domiciliar torna-se a melhor maneira de enfretamento do vírus, para essa mulher em situação violência é considerado uma "panela de pressão", com uma válvula defeituosa que a qualquer momento pode resultar em explosão, com fatídica morte por feminicídio (Silva et al., 2020).

Assim sendo, a pandemia ocasionada pelo novo coronavírus, tem ocasionado problemas sociais e de ordem financeira em todo mundo. Considerado como uma das principais estratégias conforme infectologistas e especialistas, o isolamento social passou a minimizar o índice de morbidade e mortalidade vinculada ao vírus. Contudo, nesse cenário de isolamento social encontra-se a violência contra mulher, na qual o Estado e a sociedade de maneira consciente e cautelosa devem se mobilizar para garantir que se evite, além dos agravos ocasionados pela Covid-19, as mortes por feminicídio. Além disso, deva garantir que mulheres brasileiras vivam sem violência, não mortas por seus companheiros de confinamento, portanto é tanto caso de direitos humanos, como de saúde pública. Pois, ambos estes cenários, causam morbidade e mortalidade tal qual o vírus, revelando ser uma epidemia estrutural, na qual mantém a sua curvatura de forma escalonada (Maranhão, 2020).

Fato este lembrado, por Doutor Tedros Adhanom Ghebreyesus, diretor geral da Organização Mundial de Saúde, em entrevista no dia 3 de Abril de 2020, pedindo para que os países considerem como essenciais os serviços de combate à violência doméstica, devendo continuar em pleno funcionamento durante a busca por respostas ao fim da Covid-19. Sendo pontuado por muitas (os) pesquisadoras (es)do tema em seus estudos publicados no ano de 2020, as subnotificações aparentam serem maiores que dados oficiais. Assim sendo, nota-se a necessidade de rapidez das medidas emergenciais (Moraes, 2020).

\subsection{Onde estão as políticas públicas? Rede de atendimento e enfrentamento da violência contra a mulher na pandemia}

No contexto de pandemia e isolamento social, a violência contra a mulher se intensifica cada dia mais. Então surgem as seguintes perguntas: onde estão as políticas públicas para enfrentamento da violência doméstica contra as mulheres neste contexto? O que está sendo feito para transformar e mudar essa realidade? Como está funcionando a rede de atendimento e quais estratégias estão sendo usadas?

Para responder a essas perguntas é preciso inicialmente explicar as políticas públicas abordando as formas de enfrentamento já existentes para o combate da violência diariamente. As políticas públicas, segundo Dias \& Matos (2012), significam a gestão de problemas em sociedade e a busca de resolução para demandas coletivas, usando metodologias que identifiquem as prioridades.

A pauta dos direitos das mulheres e o combate a violência tem sido levantada há um tempo pelos movimentos de 
mulheres no Brasil, para compor a agenda pública. Por esse motivo, as políticas públicas de gênero têm se destacado enquanto temática de investigação por conta da urgência das questões que se pretende resolver (Nunes, 2017).

Frente a isso, houve a promulgação da Lei Maria da Penha (11.340/2006) que se materializou por meio da institucionalização das políticas públicas para mulheres e, esta, se concretizou com a criação da Secretaria de Políticas para Mulheres, ganhando status de ministério. Essa lei cria mecanismos para coibir e prevenir a violência doméstica e familiar contra a mulher. A criação desta legislação se torna uma base de grande importância para o enfrentamento de violência contra mulher no espaço privado (Brasil, 2006).

Com isso, de acordo com Nunes (2017) essa lei é efetivada por meio das políticas públicas de enfrentamento à violência contra mulheres sendo iniciativas essenciais. Para isso sua implementação deve envolver todas as esferas de governo e atores não governamentais. $\mathrm{O}$ acesso pleno a direitos pelas mulheres depende da colaboração e do trabalho articulado entre todos os entes federativos, os Três Poderes (executivo, legislativo e judiciário) e a sociedade civil.

Visto isso, para que as políticas públicas pudessem ser concretizadas foi criado, em 2003, a Secretaria de Políticas para as Mulheres, por meio da Lei $n^{\circ} 10.683$, de 28 de maio de 2003 (BRASIL, 2003), instituída com o intuito de erradicar todas as formas de desigualdade que atingem as mulheres. Entretanto, a secretaria só teve a sua competência definida em 2010, por meio da Lei ${ }^{\circ}$ 12.314, que alterou a lei anterior transformando a Secretaria de Políticas para as Mulheres em ministério (Brasil, 2010).

Além disso, foram definidas as áreas que comporiam a Secretaria de Políticas para as Mulheres, por meio do Decreto $n^{\circ}$ 8.030, sendo elas: a Secretaria de Políticas do Trabalho e Autonomia Econômica das Mulheres; a Secretaria de Enfrentamento à Violência contra as Mulheres; e a Secretaria de Articulação Institucional e Ações Temáticas. Porém, este decreto foi revogado e substituído pelo Decreto nº 9.980, de 2019.

Já no que se refere ao atendimento e enfrentamento da violência doméstica, tem como intuito efetivar os quatro eixos que constam na Política Nacional de Enfrentamento à Violência contra as Mulheres que são: combate, prevenção, assistência e garantia de direitos, bem como atender a complexidade do fenômeno da violência contra as mulheres (Brasil, 2011).

Nesse sentido, existem a rede de enfrentamento e a rede atendimento à violência contra as mulheres. A primeira se refere à ação e atuação articulada entre as instituições e serviços governamentais, não-governamentais juntamente com a comunidade. O objetivo dessa rede diz respeito a desenvolver estratégias efetivas de prevenção e políticas que garantam o empoderamento e a construção da autonomia das mulheres, os seus direitos humanos, a responsabilização dos agressores e a assistência às mulheres que se encontrem em situação de violência. Já a rede de atendimento se volta ao conjunto de ações e serviços de diferentes setores, em especial, da assistência social, da justiça, da segurança pública e da saúde que visam à ampliação e à melhoria da qualidade do atendimento (Brasil, 2011).

Assim, diante do contexto atual de pandemia, o Conselho Nacional de Justiça publicou que a rede de enfrentamento vai aperfeiçoar o atendimento às vítimas de violência doméstica, por conta das dificuldades que as mulheres enfrentam para ter acesso à Justiça em tempos de Covid-19 pelo medo de sair de casa. Portanto, a rede de enfrentamento à violência doméstica está ampliando seus canais de divulgação e otimização dos andamentos de trabalhos para que a mulher em situação de violência, que se encontra em isolamento social por conta do coronavírus, seja atendida com maior rapidez nas delegacias no momento da denúncia do agressor e ao solicitar medida protetiva que requer urgência. O primeiro passo para essas ações foi dado no dia 01 de Abril de 2020, quando os integrantes da rede se reuniram em uma videoconferência (Conselho Nacional de Justiça, 2020)

A otimização do fluxo do atendimento pretende garantir maior agilidade na articulação das redes de atendimento, como por exemplo, delegacias de polícia, atendimento no Judiciário e o monitoramento das medidas protetivas pela Patrulha Maria da Penha, da polícia militar, além do atendimento nos centros de referência, que são os locais de acolhimento onde vítimas podem ser encaminhadas (Brasil, 2020). Quanto às denúncias que ocorrem de forma presencial, durante o período de isolamento social, percebeu-se a redução em 50\% no número de registros de Boletins de Ocorrência (BO). Deste modo, a Polícia Civil decidiu 
viabilizar as denúncias de forma virtual, que podem ser feitas pelo site: http://dv.pc.pi.gov.br/index.php. Além disso, houve a ampliação dos horários de atendimento pelos órgãos competentes, divulgação dos canais de denúncias e atendimento com cartazes em pontos estratégicos como supermercados e farmácias, a ampliação das estratégias de acolhimento às mulheres vítimas de violência no distanciamento social com o agressor (Piauí, 2020).

Portanto, os canais de comunicação vêm sendo usados para complementar as ações da rede de combate e de atendimento às mulheres em situação de violência doméstica. Para tal, utiliza-se de conteúdo diferente de acordo com o veículo de comunicação. Nas redes sociais estão sendo divulgados vídeos, posts, informativos, preventivos, interativos e de palestras realizadas ao vivo nas redes sociais para dialogar sobre temáticas relacionadas a gênero, os canais de denúncias às mulheres vítimas de violência doméstica, bem como do fortalecimento para a prática da denúncia. O objetivo dessa conexão entre as redes virtuais é repassar posts, mensagens e áudios informativos e etc.

$\mathrm{Na}$ cidade de Teresina/PI, encontram-se alguns exemplos de ações visando garantir os princípios descritos anteriormente. O poder público local realiza a divulgação de áudios informativos realizados por profissionais da Secretaria Municipal de Políticas Públicas para as Mulheres (SMPM) e da rede de atendimento à mulher em situação de violência e demais públicos. Utilizando também os veículos de comunicação em massa como espaço de divulgação das ações da Secretaria desenvolvidas no período de isolamento social. Ofertando também, via telefone, o atendimento psicossocial e jurídico, com a realização de escuta especializada, encaminhamentos e orientações para as mulheres em situação de violência por meio de uma equipe multiprofissional do Centro de Referência a Mulher em Situação de Violência. E, por fim, desenvolvendo campanhas como "\#emdefesadelas", direcionada para a divulgação do canal de comunicação do Centro de Referência à Mulher em Situação de Violência, junto aos estabelecimentos e serviços considerados essenciais (Piauí, 2020).

\subsection{Como proteger as mulheres da violência no contexto de isolamento da Covid-19}

Considerando o grave contexto epidemiológico da Covid-19, diante de uma lenta campanha da vacinação no Brasil e da ausência de um remédio próprio para combatê-lo, é possível observar um cenário de incertezas e enormes desafios. As medidas necessárias e possíveis de serem adotadas, como o distanciamento e o isolamento social, têm sido a recomendação das autoridades sanitárias internacionais e nacionais no que tange à melhor forma de contê-la. Embora haja por parte do governo federal uma relutância em fazê-la, essas ações são amplamente defendidas e adotadas por outras esferas estaduais e municipais pelo Brasil (OMS, 2020).

Conforme já explicitado, desde a promulgação da Lei nº 13.979, de 6 de fevereiro de 2020, que dispõe sobre as medidas a serem adotadas no enfrentamento do coronavírus; da Medida Provisória (MP) n 926, de 2020 que dispõe sobre os procedimentos para aquisições destinadas ao enfrentamento da Covid-19; e da ADI 6341 imposta em relação a edição dessa MP, que dentre outras coisas, restringe a liberdade de prefeitos e governadores na tomada de ações contra a pandemia e que teve decisão desfavorável ao governo federal proferida pelo Superior Tribunal Federal STF. A recomendação e adoção do isolamento social têm representado uma drástica alteração na vida cotidiana, quem pode, e em alguns casos quem é obrigado, tem ficado em casa.

Considerando os dados levantados pelo Fórum Brasileiro de Segurança Pública acerca do estudo feito para analisar os impactos do isolamento social na vida das mulheres em situação de violência revela números alarmantes em relação as denúncias. Dados coletados nos estados do Acre, São Paulo, Mato Grosso, Rio Grande do Norte e Pará, assim como pela PM de São Paulo, percebe-se um crescimento de 9\% nas denúncias ao disque 100, segundo o Ministério da Mulher, da Família e dos Direitos Humanos e uma redução nos números de medidas protetivas previstas na Lei Maria da Penha (São Paulo, 2020).

Nesse sentido, diversos setores da sociedade, organizações sociais e governos tem refletido sobre como proteger as mulheres da violência doméstica no contexto da Covid-19.No entanto, pouco ou quase nada tem sido feito no sentido de proteger 
a vida das mulheres, levando em conta os instrumentos já existentes para a prevenção e combate à violência doméstica contra a mulher, a exemplo da própria Lei Maria da Penha. Dessa forma, se faz necessário a articulação do poder público e da sociedade civil, gerando processos de produção, envolvendo os conjuntos mais amplos ou restritos de atores relevantes (Marques, 2019).

Nesse aspecto, a ONU Mulheres (2020) ao tratar dessa questão de violência como uma pandemia invisível, entende que a mesma requer tratamento urgente. A entidade ainda emitiu uma série de recomendações, como adoção de medidas incorporadas nos pacotes de apoio econômico que reflitam as necessidades das mulheres, bem como de que se priorize os serviços de prevenção e resposta à violência de gênero nas comunidades afetadas pela Covid-19. Esses serviços de prevenção que devem ser aprimorados, perpassam desde linhas de ajuda, de apoio psicossocial e de aconselhamento on-line, serviços policiais e de justiça bem como o setor privado que também é importante, e deve compartilhar informações.

A Organização das Nações Unidas reforça que essas devem ser medidas adotadas por todos os Estados, que ao direcionarem os esforços para conter a ameaça da Covid-19 não devem se esquecer das mulheres e das crianças vítimas de violência doméstica (ONU, 2020). Seguindo essa linha de recomendação, diversos países adotaram ou reforçaram as suas políticas públicas para apoiar mulheres e crianças nesse contexto de pandemia.

A França adotou medidas que vão desde o pagamento de hotel para vítimas de violência a abertura de centros de aconselhamento em mercados e farmácias. A Suíça, por meio da Secretaria de Promoção da Igualdade de Gênero e de Prevenção de Violências Domésticas de Genebra tem realizado campanhas com apelo à vigilância solidária, para que vizinhos chamem a polícia e denunciem casos em que ouçam brigas violentas ao seu redor e que envolvam mulheres, além de intensa divulgação dos canais telefônicos que servem para realizar essas denúncias (Pessoa; Nascimento, 2020).

A despeito disso, em comparação com esses países citados, pouco tem sido feito no Brasil para prevenir e combater a violência doméstica contra a mulher. $\mathrm{O}$ esperado é que o governo federal coordene as ações de enfrentamento à violência doméstica contra as mulheres e apresente medidas efetivas e mais acessíveis, aperfeiçoando inclusive as já previstas da Lei Maria da Penha para esse contexto de pandemia. No entanto, o Distrito Federal e Estados como o do Rio de Janeiro e São Paulo agiram antes mesmo que o governo federal, mantendo o atendimento 24 horas aberto ao público, ampliando a já existência de seus serviços de delegacia eletrônica, disponibilizando o registro online para os boletins de ocorrências de violência doméstica (Bianquini, 2020).

No estado de São Paulo ainda foram criadas as Patrulhas Maria da Penha responsáveis por monitorarem mulheres em situação de violência de violência doméstica; bem como a adoção de medidas mais facilitadoras, como a celeridade do atendimento desses casos pelo Tribunal de Justiça, principalmente na concessão de medidas protetivas e intimação via rede social (São Paulo, 2020). Já no estado do Piauí, a Coordenadoria Estadual de Políticas Para as Mulheres (CEPM) lançou a campanha "Ei, Mermã", que visa alertar a população e as próprias vítimas sobre o funcionamento dos canais de combate à violência doméstica já existentes, disponibilizando um número para denúncias e para mensagens via WhatsApp com canal direto para o Centro de Referência Francisca Trindade (Piauí, 2020).

Enquanto isso, o governo federal anunciou a criação de um aplicativo, já disponível, intitulado de Direitos Humanos BR, e recomendou por meio do Ofício $\mathrm{n}^{\circ} 1$ de 2020 do DEV/SNPM/MMFDH algumas medidas a serem adotadas. A exemplo disso se criou a implementação de comitês de enfrentamento à violência contra as mulheres no contexto da Covid-19, a realização de campanhas sobre a importância da denúncia, artes de adesivos para veículos e motociclistas, com o objetivo de divulgar os números dos canais de atendimento, disque 100 e o ligue 180 (Brasil, 2020).

No Congresso Nacional tem sido discutido a alteração da Lei Maria da Penha por meio do Projeto de Lei 1267/2020 que visa ampliar durante a pandemia da Covid-19 a divulgação do Disque 180, inclusive na televisão, na internet e nos rádios. Contudo, vale mencionar que essas ações por parte do governo federal, a exemplo do que recomenda a ONU Mulheres, devem ser pensadas dentro dos pacotes de apoio econômico que reflitam as necessidades das mulheres, isto é, devem estar articuladas 
com outras políticas públicas e devem gozar de recursos próprios voltados para essa questão (Brasil, 2020).

Nesse aspecto, deve-se ainda considerar que as mulheres são diversas (Butler, 2016; Perez; Ricoldi, 2018; Hooks, 2018), e que por isso requerem a adoção de medidas de acordo com a realidade de suas demandas. Conforme documento do Instituto de Pesquisa Econômica Aplicada -Ipea, a orientação para adoção dessas medidas deve seguir uma perspectiva interseccional, pois “as estruturas do gênero estão entrelaçadas com outras estruturas sociais" (Connell; Pearse, 2015, p.176), e por permitir que sejam condicionadas principalmente em relação à questão racial (Pires, 2020).

\section{Conclusão}

A violência contra a mulher, apesar de ser resultado de um processo de construção social de uma sociedade patriarcal, machista, sexista e misógina, vem nos últimos anos sendo alvo das mais variadas formas de combate e enfrentamento por parte daqueles que compõem as redes de proteção aos direitos das mulheres, entre eles, a manutenção da vida. É necessário que esse enfrentamento seja contínuo, naturalizado dentro da nossa sociedade.

Para tanto, é preciso que esses direitos, citados no corpo deste trabalho, para além de serem conhecidos, sejam reconhecidos pela população e, principalmente, pelas mulheres; e que a partir desse reconhecimento, as redes de proteção à essa mulher sejam ativadas. Cabe então às instituições exercerem o seu papel enquanto representantes do Estado, se fazendo presentes e acessíveis, o que nos faz questionar se o acesso às redes de proteção à mulher vem sendo garantido. É preciso compreendermos que não basta a existência de uma legislação específica e de uma política pública voltada para o tema, é necessário fazê-las chegarem até sua população-alvo, ou garantir que esta tenha o acesso garantido ao aparato de proteção previsto.

Diante desse contexto de mitigação de direitos e de barreiras do acesso às redes de proteção, surge uma nova perspectiva, a presença de uma pandemia que traz consigo a necessidade de um isolamento social como forma de prevenção à disseminação acelerada de um vírus. Nesse novo contexto alguns questionamentos emergem, dentre eles, questionamos o que vem sendo feito para garantir a aplicabilidade de toda a política pública de proteção da mulher contra a violência nesse momento de pandemia causada pelo Covid-19.

Podemos verificar então, com base em estudos, portarias e normativas analisadas nesta pesquisa, que embora frágil, as instituições têm buscado alternativas, baseadas em tecnologia, comunicação, mídias digitais e outras formas de mídias, para tentar sanar as dificuldades de acesso às instituições e aparatos públicos por parte destas mulheres vítimas de violência. No entanto, é preciso que essa rede seja fortalecida.

\section{Referências}

Anjos, J. C. (2019). Brasil: uma nação contra as suas minorias. Revista de Psicanálise da SPPA, 26(3), 507-522.

Bardin, L. (2016). Análise de Conteúdo. Tradução: Luís Augusto Pinheiro. São Paulo: Edições 70.

Bezerra, A. C. V., Silva, C. E. M. D., Soares, F. R. G., \& Silva, J. A. M. D. (2020). Fatores associados ao comportamento da população durante o isolamento social na pandemia de COVID-19. Ciência \& Saúde Coletiva, 25, 2411-2421.

Bianquini, H. (2020) Combate à violência doméstica em tempos de pandemia: o papel do Direito. Revista Consultor Jurídico, 24 de Abril de 2020. https://www.conjur.com.br/2020-abr-24/direito-pos-graduacao-combate-violencia-domestica-tempos-pandemia.

Brasil. (2006). Lei $N^{o} 11.340$, de 7 de Agosto de 2006. Cria mecanismos para coibir a violência doméstica e familiar contra a mulher, nos termos do $\S 8^{\circ}$ do art. 226 da Constituição Federal. 2006. Brasília: DF.

Brasil. (2010). Lei $N^{o} 12.314$, de 19 de Agosto de 2010.Altera as Leis $\mathrm{n}^{\text {os }} 10.683$, de 28 de maio de 2003, que dispõe sobre a organização da Presidência da República e dos Ministérios, 8.745, de 9 de dezembro de 1993, que dispõe sobre a contratação por tempo determinado para atender a necessidade temporária de excepcional interesse público, e 8.029, de 12 de abril de 1990, que dispõe sobre a extinção e dissolução de entidades da administração pública federal; revoga dispositivos da Lei n ${ }^{\circ} 10.678$, de 23 de maio de 2003; e dá outras providências. Brasília: DF.

Brasil. (2003). Lei $N^{o}$ 10.683, de 28 de Maio de 2003. Dispõe sobre a organização da Presidência da República e dos Ministérios, e dá outras providências. Brasília: DF. 
Brasil. (2011). Presidência da República. Secretaria Nacional de Enfrentamento à Violência contra as Mulheres. Rede de Enfrentamento à Violência contra as Mulheres. Brasília: DF.

Brasil. (2020). Rede de enfrentamento vai otimizar atendimento às vítimas de violência contra as mulheres. Notícias do Judiciário / Agência CNJ de Notícias, Brasília: DF, 02 de Abril de 2020. https://www.cnj.jus.br/rede-de-enfrentamento-vai-otimizar-atendimento-as-vitimas-de-violencia-domestica/.

Brasil. (2020). Lei $n^{\circ} 13.979$, de 6 de fevereiro de 2020. Dispõe sobre as medidas para enfrentamento da emergência de saúde pública de importância internacional decorrente do coronavírus responsável pelo surto de 2019. DOU de 7.2.2020. Brasília: DF.

Brasil. (2020). Medida provisória $n^{\circ}$ 926, de 20 de março de 2020. Altera a Lei $\mathrm{n}^{\circ} 13.979$, de 6 de fevereiro de 2020, para dispor sobre procedimentos para aquisição de bens, serviços e insumos destinados ao enfrentamento da emergência de saúde pública de importância internacional decorrente do coronavírus. DOU de 20.3.2020 - Edição extra- G. Brasília: DF.

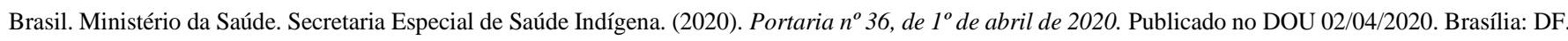

Brasil. Ministério da Mulher, da Família e dos Direitos Humanos. Secretaria Nacional de Políticas para Mulheres. (2020). Ofício-circular $n^{o}$ 1/2020/dev/snpm/mmfdh. Recomendações em relação às ações de enfrentamento à violência contra meninas e mulheres no contexto da pandemia de COVID19. Brasília: DF.

Brasil. (2020). PL 1267/2020. Altera a lei 10.714/2003, com o objetivo de ampliar a divulgação do Disque 180 enquanto durar a pandemia do covid-19 (novo coronavirus). Brasília: DF.

Butler, J. (2003). Problemas de gênero: feminismo e subversão da identidade. Tradução, Renato Aguiar. — Rio de Janeiro: Civilização Brasileira.

Butler, J. (2016). Capítulo I- Sujeitos do sexo/gênero/desejo. In: Problemas de gênero: feminismo e subversão da identidade. Rio de Janeiro: Civilização brasileira.

Connell, R.; Pearse, R. (2015). Gênero: uma perspectiva global. São Paulo: nVersos.

Cubas, M. G.; Zaremba, J.; Amâncio, T. (2019). Brasil registra 1 caso de agressão a mulher a cada 4 minutos, mostra levantamento. Folha de S.Paulo. São Paulo, 9 de Novembro de 2019. <https://www1.folha.uol.com.br/cotidiano/2019/09/brasil-registra-1-caso-de-agressao-a-mulher-a-cada-4-minutos-mostralevantamento.shtml>.

Conselho Nacional de Justiça. (2020). Rede de enfrentamento vai otimizar atendimento às vítimas de violência doméstica. https://www.cnj.jus.br/rede-deenfrentamento-vai-otimizar-atendimento-as-vitimas-de-violencia-domestica/

Dias, R.; Matos, F. (2012). Políticas Públicas: Princípios Propósitos e Processos. São Paulo: Atlas.

Durkheim, E. (1978). O que é fato social. Durkheim E, organizador. As regras do método sociológico. São Paulo: Abril Cultural, 87-109.

Hirata, H. (2018). Gênero, patriarcado, trabalho e classe. Revista Trabalho Necessário, 16(29), 14-27.

Hooks, B. (2018). O feminismo é para todo mundo: políticas arrebatadoras. Rio de Janeiro: Rosa dos tempos.

Maranhão, R. A. (2020). A violência doméstica durante a quarentena da COVID-19: entre romances, feminicídios e prevenção. Brazilian Journal of Health Review, 3(2), 3197-3211.

Marconi, M. A.; Lakatos, E. M. (2010). Fundamentos de metodologia científica. São Paulo: Editora Atlas.

Marques, E. S., Moraes, C. L. D., Hasselmann, M. H., Deslandes, S. F., \& Reichenheim, M. E. (2020). A violência contra mulheres, crianças e adolescentes em tempos de pandemia pela COVID-19: panorama, motivações e formas de enfrentamento. Cadernos de Saúde Pública, 36, e00074420.

Marques, E. C. L. (2019). Notas sobre redes, Estado e políticas públicas. Cadernos de Saúde Pública, 35, e00002318.

Melo, B. D, Lima, C. C., Moraes, C. L., Andrade, C. B., Pereira, D. R., Souza, E. R., Ribeiro, F. M. L., Serpeloni, F., Avanci, J. Q., Kabad, J. F., Njaine, K., Deslandes, S. F., Schenker, M., Souza, M. S., Magrin, N. O., Assis, S. G., Zanello, V., Silva, V. L. M., Kadri, M., Rabelo, I. V. M. (2020). Saúde mental e atenção psicossocial na pandemia COVID-19: violência doméstica e familiar na COVID-19. Rio de Janeiro: Fiocruz.

Minayo, M. C. S. (2013). O desafio do conhecimento: pesquisa qualitativa em saúde. 13. ed., São Paulo: Hucitec.

Moraes, R. F. (2020). Nota Técnica n. 27 (Diest) :Prevenindo conflitos sociais violentos em tempos de pandemia: garantia da renda, manutenção da saúde mental e comunicação efetiva. Ipea, Brasília: DF.

Nunes, A. J., \& Sales, M. C. V. (2016). Violência contra crianças no cenário brasileiro. Ciencia \& saude coletiva, 21, 871-880.

Nunes, A. C. A. S. (2017) Análise de arranjos de implementação de políticas públicas de enfrentamento à violência contra mulheres em municípios de pequeno porte. Revista do Serviço Público - RSP, 68(3), 503-532.

Okabayashi, N. Y. T., Tassara, I. G., Casaca, M. C. G., de Araújo Falcão, A., \& Bellini, M. Z. (2020). Violência contra a mulher e feminicídio no Brasil-impacto do isolamento social pela COVID-19. Brazilian Journal of Health Review, 3(3), 4511-4531.

Organização Mundial da Saúde (OMS). (2020). Organização Pan-Americana de Saúde (OPAS). Folha Informativa - COVID 19. https://www.paho.org/bra/index.php?option=com_content\&view=article\&id=6101:covid19\&Itemid=875.

Paz, P. O., Pires, N. S., Vieira, L. B., \& Witt, R. R. (2019). Vulnerabilidade de mulheres em situação de violência atendidas em serviço especializado. Aquichan, 19(2), 2. 
Research, Society and Development, v. 10, n. 5, e27410514696, 2021 (CC BY 4.0) | ISSN 2525-3409 | DOI: http://dx.doi.org/10.33448/rsd-v10i5.14696

ONU Mulheres. (2020). Gênero e covid-19 na américa latina e no caribe: dimensões de gênero na resposta. BRIEF - Março 2020. Brasília: DF.

Perez, O.; Ricoldi, (2018). A. A quarta onda do feminismo? Reflexões sobre movimentos feministas contemporâneos. In: Anais. 42 ${ }^{\circ}$ Encontro Anual da ANPOCS, Caxambu-MG.

Pessoa, B. G. F; \& Nascimento, E. F. (2020). Feminicídio e Covid-19. Revista Espaço Acadêmico, 20(224), $37-46$.

Piauí. Coordenadoria de Estado de Políticas para Mulheres. (2020). Distribuição de material Campanha Ei, mermã! http://www.cepm.pi.gov.br/noticia.php?id=203.

Piauí. Prefeitura Municipal de Teresina. (2020). Secretaria Municipal de Políticas Públicas para Mulheres. Disponível em: https://smpm.pmt.pi.gov.br/.

Pires, R. R. C. (2020). Nota Técnica n. 33 (Diest) : Os Efeitos sobre grupos sociais e territórios vulnerabilizados das medidas de enfrentamento à crise sanitária da Covid-19 : propostas para o aperfeiçoamento da ação pública. Ipea, Brasília: DF.

Santos, C. M., \& Izumino, W. P. (2005). Violência contra as mulheres e violência de gênero: notas sobre estudos feministas no Brasil. Estudios interdisciplinarios de América Latina y el Caribe, 16(1).

São Paulo. (2020). Lei $n^{\circ} 17.260$, de 30 de março de 2020. Dispõe sobre a criação do programa da Polícia Militar "Patrulha Maria da Penha", que visa ao monitoramento da segurança das mulheres vítimas de violência doméstica no Estado de São Paulo. DO - ExecutivoExecutivo, 31/03/2020, p.1. https://www.al.sp.gov.br/norma/193406.

Sawaia, B. (2017). As artimanhas da exclusão: análise psicossocial e ética da desigualdade social. Editora Vozes Limitada.

Silva, A. F. C., Alves, C. G., Machado, G. D., Meine, I. R., Silva, R. M. da, \& Carlesso, J. P. P. (2020). Violência doméstica contra a mulher: contexto sociocultural e saúde mental da vítima. Research, Society and Development, 9(3), e35932363.

Teles, M. A. A., \& de Melo, M. (2017). O que é violência contra a mulher. Brasiliense. 